\title{
Review Article \\ Trans-Species Polymorphism in Immune Genes: General Pattern or MHC-Restricted Phenomenon?
}

\author{
Martin Těšický and Michal Vinkler \\ Charles University in Prague, Faculty of Science, Department of Zoology, Viničná 7, 12844 Praha, Czech Republic \\ Correspondence should be addressed to Michal Vinkler; michal.vinkler@natur.cuni.cz
}

Received 25 March 2015; Accepted 4 May 2015

Academic Editor: Nejat K. Egilmez

Copyright (C) 2015 M. Těšický and M. Vinkler. This is an open access article distributed under the Creative Commons Attribution License, which permits unrestricted use, distribution, and reproduction in any medium, provided the original work is properly cited.

\begin{abstract}
Immunity exhibits extraordinarily high levels of variation. Evolution of the immune system in response to host-pathogen interactions in particular ecological contexts appears to be frequently associated with diversifying selection increasing the genetic variability. Many studies have documented that immunologically relevant polymorphism observed today may be tens of millions years old and may predate the emergence of present species. This pattern can be explained by the concept of trans-species polymorphism (TSP) predicting the maintenance and sharing of favourable functionally important alleles of immune-related genes between species due to ongoing balancing selection. Despite the generality of this concept explaining the long-lasting adaptive variation inherited from ancestors, current research in TSP has vastly focused only on major histocompatibility complex (MHC). In this review we summarise the evidence available on TSP in human and animal immune genes to reveal that TSP is not a MHCspecific evolutionary pattern. Further research should clearly pay more attention to the investigation of TSP in innate immune genes and especially pattern recognition receptors which are promising candidates for this type of evolution. More effort should also be made to distinguish TSP from convergent evolution and adaptive introgression. Identification of balanced TSP variants may represent an accurate approach in evolutionary medicine to recognise disease-resistance alleles.
\end{abstract}

\section{Introduction}

Immune function is highly heritable [1-4], governed from a large proportion by combination of alleles encoding functionally relevant immune-related molecules [5-7]. The alleles of immune genes coevolve in interaction with pathogens attacking the organism [8]. According to the Red Queen hypothesis pathogens form constant pressure on host population, selecting in many cases on variability within immune genes [9]. Genetic variability underlying the selected heterogeneity in the immune function is observable in the host as allelic polymorphism, that is, a long-lasting occurrence of two or more genotypes in a population in frequencies that cannot be attributed to a recurrent mutation [10]. Long-lasting polymorphism may be maintained in the human and animal host populations by balancing selection [11-13]. Intriguingly, this polymorphism maintained by selection may be shared across species and even between higher evolutionary lineages such as genera or rarely families [14-18]. This sharing of immunologically important genetic variation may have then profound effects on the interspecific similarity of naturally occurring ranges of immune responsiveness upon specific antigen stimulation.

Trans-species polymorphism (TSP) refers to the occurrence of identical or similar alleles in related species, excluding instances where the similarity arose by convergence or introgression $[19,20]$. By definition, TSP alleles in related species are more similar in their sequences than are the alleles within individual species. TSP arises from the passage of alleles from ancestral species to descendant species by incomplete lineage sorting [19-21] (see also in Figure 1). Generally, we distinguish two forms of TSP, neutral TSP and balanced TSP. Neutral (transient) TSP is frequent in closely related newly diverged species and gradually disappears [19]. Thus, neutral TSP has a tendency to be widespread across loci only in a short window of time after the speciation event $[22,23]$. In contrast, balanced TSP is functionally much more important [20]. This type of TSP results from balancing selection, that is, selection for variability maintenance. Balanced TSP is typically long-lasting and may be maintained in immune 


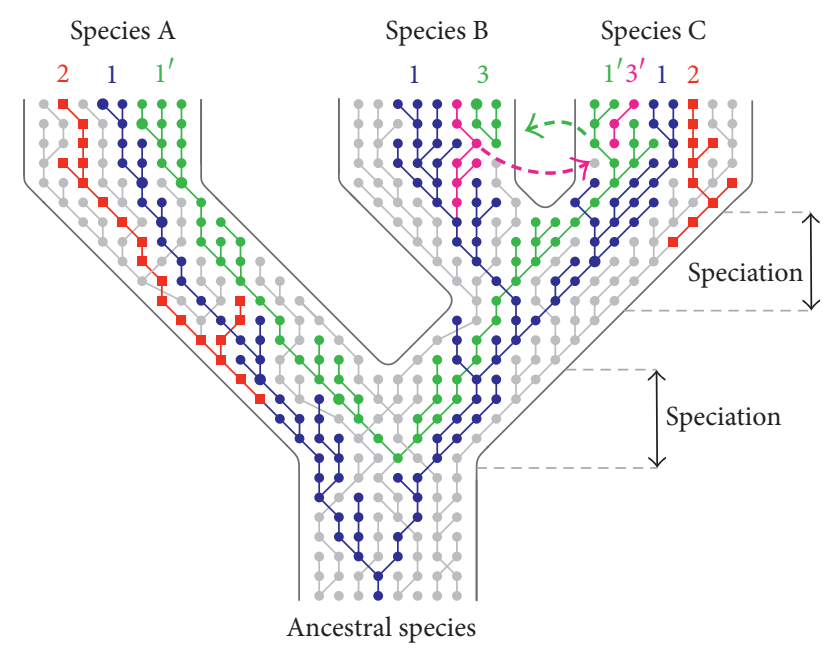

FIgURE 1: Mechanisms explaining polymorphism shared between taxa (based on $[19,112])$. The three proposed mechanisms are depicted in alleles' genealogy: (1) trans-species polymorphism, TSP (incomplete lineage sorting; allelic lineages predate speciation and are passed to descendent species), (2) convergence (allelic lineages evolve similar features independently in separate lineages), and (3) introgression (allelic lineages are horizontally transferred either from recipient species to donor species or in both directions). Each row depicts a gene pool of one generation, each circle/square an allele of specific features. Different colours highlight individual allelic lineages, where interconnecting lines mark antecedentdescendent relationships. Green and purple dashed arrows represent directions of introgression.

genes for millions or even tens of millions of years [2426]. Identification of balanced TSP variants is, therefore, a powerful approach to identify naturally occurring resistance alleles with application potential in human medicine as well as in animal breeding and nature conservation.

The TSP concept was proposed three decades ago by Klein [27] who supported its existence by comparative evidence in major histocompatibility complex (MHC, $\mathrm{H} 2$ antigen) in mice [28]. Until present, MHC alleles from many mutually related species were sequenced and the TSP phenomenon was reported in numbers of studies in all sorts of taxa (see Supplement 1 in Supplementary Material available online at http://dx.doi.org/10.1155/2015/838035). Surprisingly, our knowledge on TSP in other immune gene classes is only limited. Is TSP unique to MHC or does it represent a general evolutionary pattern masked by little endeavour paid to its investigation outside the MHC family? In the present review we compile present evidence on TSP in human and animal immune genes and outline main directions for further evolutionary immunogenetic research.

\section{Evolutionary Mechanisms Maintaining Balanced TSP in Immune Genes}

Long-lasting TSP in immune genes is dependent on balancing selection. This type of selection maintains genetic variation in populations for extensive periods of time based on three possible mechanisms: (1) heterozygote advantage $[29,30],(2)$ negative frequency-dependent selection [31, $32]$, and (3) spatio-temporally fluctuating selection [33, 34]. Heterozygote advantage (also termed overdominance) arises when individuals heterozygous in a particular gene are able to resist the pathogen infection better than both homozygotes. In this case polymorphism is maintained by selection for heterozygosity. Overdominance is well described for MHC genes in a number of species where the benefits of heterozygosity in certain loci depend on the degree of overlap in binding specificity of individual alleles [30,35]. Negative frequencydependent selection, in contrast, represents a mechanism where only particular genotypes provide resistance advantage in a given time. This advantage is, nevertheless, negatively linked to the allele frequencies in a population [31]. It has been repeatedly shown that pathogens tend to infect and adapt to the most common genotypes of the host in a population, leaving out rare genotypes [36]. Rare alleles are, therefore, favoured and increase in frequency until they reach a specific equilibrium beyond which they start to be selected against. Frequencies of the alleles thus oscillate in time and balanced polymorphism is maintained [12,30]. Empiric supports come from associations of MHC alleles of susceptibility to diseases $[30,35,36]$. Finally, fluctuating selection is based on variation in selective pressures in space and time. Most pathogens are present in a limited area of distribution and their abundance change in time (spatio-temporal fluctuations). This creates distinct and changing selective pressures on different host populations that may be, nonetheless, linked by migration $[33,34]$. In contrast to the negative frequency-dependent selection, in fluctuating selection the fitness value changes as a function of particular pathogen abundance and not as a function of the allele frequency itself [33]. Although there is still serious lack in empirical evidence supporting the existence of fluctuating selection, theoretical approaches suggest that this mechanism is admissible, for instance, for the maintenance of the MHC polymorphism [12]. The three mechanisms of balancing selection are not mutually exclusive and in all perceivable combinations all may be involved in the maintenance of the balanced TSP.

\section{TSP in Major Histocompatibility Genes (MHC)}

MHC groups several extremely polymorphic and dynamically evolving members of the immunoglobulin superfamily playing a crucial role in the adaptive immune defence against pathogens in jawed vertebrates [29, 37]. MHC genes encode cytoplasm-membrane-bound glycoproteins which present endogenous and exogenous oligopeptides to $\mathrm{T}$ cells [38]. Although the strength of the association between MHC polymorphism and resistance to infectious diseases varies between species and populations $[39,40]$, the capability of certain alleles to bind certain pathogen-derived peptides is undoubtedly essential for individual survival [30]. The type of the selection responsible for the variability maintenance linked to disease resistance may, however, not only be natural selection but also sexual selection $[31,41]$, since the two mechanisms are not mutually exclusive and both can contribute to 
TABLE 1: Number of published research articles dealing with TSP in vertebrate immune genes available on Web of Science, final update 19 March 2015. For details see Supplement 1.

\begin{tabular}{lcc}
\hline Gene group & Gene & Number of references \\
\hline & Classical MHC I: HLA-A, -B, -C, MHC Ia undifferentiated & 27 \\
Major histocompatibility complex (MHC) & Non-classical MHC I: HLA-E, -G & 2 \\
& MHC IIA: DPA, DRA, DQA, DAA, MHC IIA undifferentiated & 36 \\
\hline & MHC IIB: DPB, DRB, DQB, DAB, DRB-like, MHC IIB undifferentiated & 80 \\
Non-MHC immunoglobulins & PSMB8 (LMP7) & 2 \\
& IGVH & 2 \\
\hline Host defence peptides & C Alfa gene & 2 \\
\hline 2-5A synthetase family & AvBD12 & 2 \\
\hline Tripartite motif protein family & OAS1b & 2 \\
\hline
\end{tabular}

balanced parasite-mediated polymorphism. The MHC gene family can be generally divided into two classes: MHC class I and MHC class II [39]. Owing to their importance in the immune response and a high variability on both interspecific and intraspecific levels, traditionally, most studies dealing with TSP have focused on MHC class I and MHC class II genes and their peptide binding regions (PBRs) in particular (summarized in Table 1 and Figure 2).

MHC class I proteins consist of a transmembrane $\alpha$ chain composed of $\alpha_{1}, \alpha_{2}, \alpha_{3}$ domains and $\beta_{2}$-microglobulin $[29,30,38]$. PBR is coded by exon 2 ( $\alpha_{1}$-domain) and exon 3 ( $\alpha_{2}$-domain) and binds shorter oligopeptide fragments (approximately 8-11 amino acids in length) originating from an intracellular pathogen or endogenous peptides. Complexes of MHC class I molecules with their peptides are recognized by $\mathrm{T}$-cell receptors (TCRs) of $\mathrm{CD} 8^{+} \mathrm{T}$ cells. $\mathrm{MHC}$ class II molecules, in contrast, consist of two noncovalently associated chains: $\alpha$ chains $\left(\alpha_{1}, \alpha_{2}\right)$ and $\beta$ chains $\left(\beta_{1}, \beta_{2}\right)$, encoded by two different genes termed MHC IIA and MHC IIB $[30,32]$. The MHC class II PBR is formed by $\mathrm{N}$-terminal domains of these molecules $-\alpha_{1}$ (exon 2) and $\beta_{1}$ (exon 2). Opened binding groove of MHC class II allows binding of longer peptides (approximately 11-17 amino acids in length) originating from extracellular pathogens or intracellular pathogens inhabiting vesicular systems $[29,30]$. Complexes of MHC class II molecules with their peptides are recognized by $\mathrm{CD}^{+}{ }^{+} \mathrm{T}$ cells $[29,38]$. However, cross presentation of antigenic peptides enables the exposure of some MHC-classII-type exogenous peptides on the binding surface of MHC class I molecules, and vice versa [38, 42].

In MHC genes TSP encompasses mainly variable exons encoding PBRs (in MHC class I exons 2 and 3, in MHC class II exon 2 of both MHC IIA and MHC IIB genes) that have been the targets of strong diversifying (increasing allele numbers) and positive (adapting the alleles to pathogenic peptides) selection followed by balancing selection modifying allele frequencies $[19,43]$. There are highly variable and divergent alleles which can persist as identical or nearly identical alleles within millions of years [16] and as allelic lineages up to tens of millions of years [19]. In contrast to PBR, non-PBR MHC domains are usually evolutionary conserved, often under purifying selection without or with minimal TSP [26, 44-46].

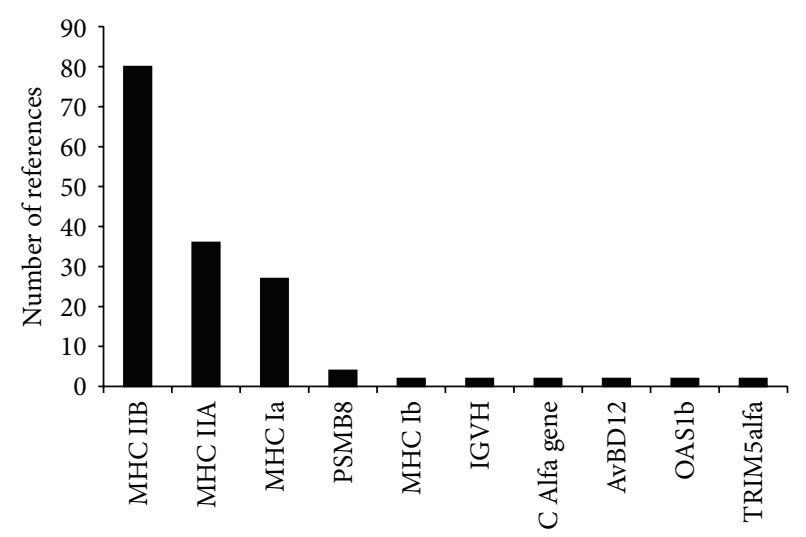

FIGURE 2: Number of published research articles dealing with TSP in vertebrate immune genes available on Web of Science, final update 19 March 2015. For details see Supplement 1.

Although evidence for TSP has been gathered from several MHC loci in mammals, birds, reptiles, amphibians, and fish indicating that TSP is a general phenomenon in MHC, the vast majority of studies focused on genotyping only the most variable exon 2 of the MHC IIB genes (Table 1 and Figure 2). In MHC IIA loci the lower number of studies reporting TSP may be explained by the general belief of their more conserved nature when compared to MHC IIB genes $[24,47,48]$. Furthermore, despite the broad range of taxa investigated, most evidence on TSP is limited to mammals (especially primates, rodents, and even-toed ungulates; see Supplement 1).

Time persistence of allelic lineages in mammalian classical MHC class I genes is assumed to be generally shorter than in classical MHC class II genes [19, 49, 50]. For instance, in primates MHC class I allelic lineages HLA-A, -B, -C are probably younger than 22 million years $[19,49]$. In contrast, some allelic lineages in primate MHC class II appear to be older than 30 million years [51]. In Lemuriformes identical MHC class II alleles of DRB exon 2 persist for more than 37-42 million years [17]. Similarly, in DQA genes in rodents, the oldest alleles are maintained for at least 48 million years [52]. Interestingly, TSP is maintained in fish, amphibians, and 
reptiles on much longer timescales than in mammals $[45,53-$ 55]. For instance, the oldest allelic lineages of exon $2 \mathrm{MHC}$ Ia that are shared between Salmoniformes and Cypriniformes precede the taxa divergence and persist for more than 145 million years [56]. The oldest reported TSP then concerns antigen presenting MHC class I within Acipenseriformes, with time persistence of 187 million years [57].

\section{Trans-Species Polymorphism in Other Immune Genes}

4.1. Non-MHC Immunoglobulins. TSP has also been described in members of the immunoglobulin superfamily other than MHC. The existence of high genetic variability and TSP in heavy chains of immunoglobulins in rabbits and hares has been predicted by serological cross reactivity among serotypes as early as in 1980s [58]. Heavy chains of immunoglobulins are encoded by the immunoglobulin variable region heavy chain (IgVH) genes [59]. Variability in these genes may affect the binding specificity of antigen binding sites of antibodies. Apart from IgVH genes directly involved in VDJ arrangements, other $\mathrm{IgVH}$ genes including pseudogenes can serve as a source of variation for gene conversion [60]. It has been shown that the IgVH TSP in the Leporid lineage concerns the VH1/VHa gene and predates the rabbit and hare divergence and persists for at least 16-24 million years, perhaps as long as for 50 million years $[58,60,61]$. Another example of TSP in the immunoglobulin superfamily has been reported among eight macaque species in exon 2 of the $\mathrm{C} \alpha$ constant region of IgA heavy chain $[62,63]$. Although previously considered as conservative, high interspecific as well as intraspecific variability has been discovered in primates [62-64]. Exon 2 encodes the hinge region which lies at the base of the heavy chain regions of immunoglobulin $[62,63]$. Variability in the hinge region associated with variation in flexibility of the molecule might affect the spectrum of antigens recognised by the antigen binding site of the IgA antibody [62] or allow avoidance of the attacks of bacterial proteases in this region $[62,65]$.

4.2. PSMB8. PSMB8 (proteasome subunit $\beta$-type 8 gene, LMP7) encodes immunoproteasomal catalytic subunit of $\beta$ ring which is involved in the cleavage of peptides processed for presentation on MHC class I molecules [66]. This gene is located in MHC class I gene cluster, and together with another proteasomal gene PSMB9 its expression is interferoninduced. Polymorphism in this gene involves amino acid position 31 that affects the catalytic function of the subunit. Two functionally distinct allelic lineages differing at this position have been distinguished in various vertebrate lineages [67]: (1) A-type PSMB8 having Ala/Val at the position 31 with a larger and opened S-pocket allowing the cleavage of aromatic amino acids with the chymotrypsin activity and (2) F-type PSMB8 having Phe/Tyr at the position of 31 with a narrower S-pocket suitable for elastase cleavage of small hydrophobic amino acids [67]. This type of TSP has been reported in PSMB8 in bony fish of the Oryzias genus [68], where two highly diverged allelic lineages differing in the sequence encoding the S-pocket (called here PSMB8N and PSMB8d) persist for at least 30-60 million years. A similar pattern has also been reported among clawed frog (Xenopus) species [69] suggesting the existence of similar independent TSP allelic lineages in amphibians for 80 million years. Intriguingly, allelic dichotomy in PSMB8 gene between Cypriniformes and Salmoniformes (PSMB8F and PSMBA) suggests extremely long-term transorder polymorphism maintained for more than 300 million years [67]. To conclude, these examples demonstrate long-term TSP in lower taxonomic units (Oryzias, Xenopus and between Salmoniformes and Cypriniformes) in genetic traits that most probably converged between major vertebrate lineages $[67,70]$.

4.3. Host Defence Peptides. Host defence peptides (HDPs, also known as antimicrobial proteins) are small, diverse, and evolutionary conserved effector molecules involved mainly in pathogen killing $[71,72]$, but also in immunomodulation, wound healing, cell development, and so forth $[73,74]$. There are many types of HDPs in all sorts of organisms [75], and HDP intraspecific sequence variability maintained by balancing selection has been reported $[76,77]$. In HDPs, TSP has been documented so far only in avian $\beta$-defensin AvBD12 gene [78]. $\beta$-defensins are amphipathic cationic cysteine-rich peptides [72]. In humans, intraspecific polymorphism in $\beta$ defensin genes affects susceptibility to pathogens, such as HIV [79]. In AvBD12 gene TSP was described in exon 3 in two passerine species: blue tits and great tits [78]. Given the limited sampling effort more widespread occurrence of TSP in HDPs cannot be excluded.

4.4. TRIM5 $\alpha$. TRIM5 $\alpha$ (tripartite motif protein $5, \alpha$ isoform) is the longest isoform of a viral restriction factor which interacts with viral capsid proteins in cytosol during retrovirus infection and thus prevents reverse transcription $[80,81]$. Similarly to MHC genes, TRIM genes are highly polymorphic and their evolution has been driven by gene loss, pseudogenization, duplication, and punctuated positive selection $[80,82]$. TRIM5 $\alpha$ consists of C-terminal SPRY/B30.2 domain, RING domain, and B-box $2 \mathrm{a}$ and coiled-coil (CC). TSP is documented among macaques in the SPRY/B30.2 domain and among biting midges (Ceratopogonidae) in the CC domain [82]. The variability in SPRY/B30.2 domain determinates restriction specificity [80], while the functional significance of the polymorphism in CC domain still remains unresolved $[80,82]$. In addition to the TSP in coding region of the gene, TSP has also been detected in intron 1, apparently maintained between humans and chimpanzees by balancing selection for 4-7 million years [83]. This TSP may affect transcriptional activity of the gene.

4.5. Oligoadenylate Synthetase. Oligoadenylate synthetases (OASs) are interferon-inducible enzymes with pleiotropic functions involved in the organism protection against retroviral infections [84]. After activation by interferons the RNAdependent $2^{\prime}, 5^{\prime}$-OAS synthesizes $2^{\prime}, 5^{\prime}$-oligoadenylates from adenosine triphosphate, which activates latent endoribonuclease RNase L leading to degradation of dsRNA and inhibition of viral replication [84]. In mice, the variability in gene 
OAS1b has functional consequences on variation in resistance against flavivirus infections, for example, to West Nile virus $[85,86]$. Species of Palearctic mice share two deeply diverged allelic lineages of OAS1b predating the split of house mouse (Mus musculus) and servant mouse (M. famulus) 2.8 million years ago. Both groups of allelic lineages provide resistance to flavivirus infections; however, the lineage of "major resistance alleles" protects against a broader spectrum of flavivirus genotypes compared to "minors resistance alleles" [87]. This TSP appears to involve only the C-terminal domain of OAS1b which is responsible for the enzyme tetramerization and protein-protein binding [87]. In contrast, the OAS1 TSP known in humans, chimpanzees, and gorillas concerns the Nterminal RNA-binding region [88].

\section{Future Directions}

TSP is a crucial evolutionary mechanism responsible for sharing adaptive genetic variation across taxa. Although presently most studies dealing with TSP have concentrated only on the MHC loci (MHC I and MHC II and their peptide binding regions, in particular), the few examples described in other immune genes suggest that TSP is a common and general evolutionary phenomenon. Indeed, besides immune genes, the TSP has been documented, for example, in self-incompatibility loci preventing self-fertilization in Angiosperms [89-91], in mating loci in fungi [92-94], in ABO blood system in primates [95-97], or in complementary sex determiner gene in Hymenoptera [98, 99]. Investigation of TSP predominantly in association with MHC thus appears to be a historically given stereotype which might have slowed down the rate of similar investigation in other families of immune genes. It has been recently proposed for humanschimpanzees that TSP is especially common in membrane glycoproteins [100]. As shown in the present review, TSP may be present in genes encoding effector molecules as well as immune receptors. The products of both gene types physically interact with pathogen molecules and are, therefore, more likely than others to evolve under balancing selection.

Further research should clearly focus more intensively on investigation of TSP patterns in innate immune genes. It has been proposed recently that at least approximately half of the genetic variability for resistance to infection is attributable to non-MHC genes [101]. We suggest that besides antimicrobial peptides, oligoadenylate synthetases, or viral restriction factors where the first evidence of TSP has been reported, further effort should be made to reveal TSP in pattern recognition receptors (PRRs). PRRs are innate immunity receptors that recognize pathogen-associated molecular patterns (PAMPs) that serve as danger signals [102]. Considering the direct physical association between PRRs and PAMPs in triggering the immune response [103], in concordance with the Red Queen hypothesis we may predict strong evolutionary pressures maintaining balanced frequencies of PRR alleles. There are many families of PRRs, toll-like receptors (TLRs), C-type lectin receptor (CLRs), RIG-like receptors (RLSs, retinoic acid-inducible gene-I-like receptors), NODlike receptors (NLRs, nucleotide-binding oligomerization domain receptors), and others [102, 104]. Despite the fact that PRRs are evolutionary relatively conserved, considerable nonsynonymous polymorphism with predicted functional significance has been recently documented in the binding sites of these receptors both on interspecific and intraspecific levels [105-109]. Recent comparison of human populations also revealed that balancing selection is the main force shaping the evolution of many innate immunity genes [110]. PRRs, hence, appear as suitable candidate genes for TSP investigation.

Although commonly assessed in gene coding regions, TSP may also be maintained in other functionally important parts of the genome, such as, for example, the promoter regulatory sequences of individual genes. It has been reported in primates that TSP may preferentially involve transcription factor binding sites regulating gene expression $[100,111]$. Our knowledge on TSP in noncoding regions is currently insufficient and further research is needed to show how widespread this type of TSP is.

When studying patterns of polymorphism on interspecific level, some caution is also needed before TSP is assigned and reported. Several evolutionary mechanisms other than balanced TSP were also proposed to explain the existence of shared polymorphism in several related taxa. These are, namely, (1) incomplete lineage sorting by chance (sometimes described as neutral or transient TSP as described in the introduction), (2) convergent evolution, and (3) genetic introgression. Distinguishing these mechanisms from TSP is one of the greatest challenges in the present TSP research $[112,113]$ (see also Figure 1). In contrast to balanced TSP and incomplete lineage sorting by chance (which is a state expected mainly in newly diverged species), convergent evolution is a process whereby organisms (related or not) independently evolve similar traits as a result of adaptation to similar environments or ecological niches [20, 32]. Although presumably common in immune genes [32, 51, 114], convergence has been shown difficult to detect. Convergent evolution usually operates in short functionally important motifs and may be, therefore, distinguished from TSP by specific coding resemblance only in these key regions [32]. Comparison of phylogenetic trees constructed based on regions with a distinct function (e.g., peptide-binding region, $\mathrm{PBR}$, sequence and non-PBR sequence of $\mathrm{MHC}$ ) may be used to differentiate between TSP and convergence $[26,51,114]$. Also the third mechanism that may be mistaken with TSP, that is, hybridization with subsequent adaptive introgression, may be far more common than generally assumed [112]. Introgression occurs mainly in evolutionary young, radiated, or closely related species with incomplete reproductive isolation mechanisms, which further complicates its differentiation from TSP. Mixing alleles of the both trans-specific and hybrid origin (that are barely distinguishable) have been reported in adaptive radiated species, in Darwin finches $[115,116]$ or cichlid fish of Haplochromis species flock of East African lakes [23]. Furthermore, hybridization can also occur in relatively diverged taxa. Almost one-tenth of bird species may hybridize [117]. There is still lack of evidence to show how common is the hybridization-linked adaptive introgression in immune genes (but see, e.g., [14, 112, 113, 118-120]). 
One of the possible ways to distinguish between adaptive introgression and TSP is to compare the relative size of the haplotype blocks of the shared polymorphism. In case of TSP we expect these blocks to be smaller than in case of the gene introgression [113, 118, 119]. Combining large data sets with novel genomic approaches such as the highly dense SNP chips or next-generation sequencing may be useful in doing so. Not only basic evolutionary research but also human and veterinary medical research may benefit from precise identification of TSP. In addition to the clear potential of TSP to identify functionally important variation in human and animal genomes (that may be associated with disease susceptibility or resistance), TSP alleles may also be linked to deleterious mutations accumulated in the neighbourhood of the sites maintained by the balancing selection [121]. Identification of beneficial and deleterious variability in genomes is essential precondition allowing complex personalised medicine in the future.

\section{Conclusion}

Taken all together, despite its importance and general applicability, in recent research the TSP concept is being commonly associated only with MHC trans-specific genetic variation. This research stereotype is unfortunate, since lacking evidence on TSP in other types of immune genes precludes our understanding of the mechanisms shaping the present genetic variability maintained by host-pathogen coevolution. Besides focusing on TSP in innate immunity genes (and mainly PRRs), more effort should also be made to distinguish true TSP from TSP-like patterns. Although originally a question of an academic interest, TSP investigation may bring practically relevant results. Identification of TSP variants is a powerful approach to identification of naturally occurring resistance alleles with application potential in human and veterinary medicine, animal breeding, and nature conservation. Recent advance of genomics in immunology allows us systematic research of TSP in all sorts of immune genes and perceiving the TSP concept as a MHC-linked mechanism would jeopardise the interpretational potential of the current immunogenetic research.

\section{Conflict of Interests}

The authors declare that there is no conflict of interests regarding the publication of this paper.

\section{Acknowledgments}

The authors are grateful to Lenka Kubíčková and Karel Kodejš and three anonymous reviewers for their helpful comments on the paper and Dagmar Vinklerová for language corrections. This study was supported by the Czech Science Foundation (Grant no. P506/15-11782S), by the Grant Agency of the Charles University (Grant no. 540214), and through the Institutional Research Support (SVV-260 208/2015).

\section{References}

[1] A. J. M. de Craen, D. Posthuma, E. J. Remarque, A. H. J. van den Biggelaar, R. G. J. Westendorp, and D. I. Boomsma, "Heritability estimates of innate immunity: an extended twin study," Genes and Immunity, vol. 6, no. 2, pp. 167-170, 2005.

[2] V. Orrù, M. Steri, G. Sole et al., "XGenetic variants regulating immune cell levels in health and disease," Cell, vol. 155, no. 1, pp. X242-X256, 2013.

[3] G. Sorci, A. P. Møller, and T. Boulinier, "Genetics of hostparasite interactions," Trends in Ecology \& Evolution, vol. 12, no. 5, pp. 196-200, 1997.

[4] G. S. Cooke and A. V. S. Hill, "Genetics of susceptibility to human infectious disease," Nature Reviews Genetics, vol. 2, no. 12, pp. 967-977, 2001.

[5] S. Buhler and A. Sanchez-Mazas, "HLA DNA sequence variation among human populations: molecular signatures of demographic and selective events," PLoS ONE, vol. 6, no. 2, Article ID e14643, 16 pages, 2011.

[6] P. A. Reche and E. L. Reinherz, "Sequence variability analysis of human class I and class II MHC molecules: functional and structural correlates of amino acid polymorphisms," Journal of Molecular Biology, vol. 331, no. 3, pp. 623-641, 2003.

[7] A. Sanchez-Mazas and D. Meyer, "The relevance of HLA sequencing in population genetics studies," Journal of Immunology Research, vol. 2014, Article ID 971818, 12 pages, 2014.

[8] P. Schmid-Hempel, Evolutionary Parasitology: The Integrated Study of Infections, Immunology, Ecology, and Genetics, Oxford University Press, New York, NY, USA, 2011.

[9] M. E. J. Woolhouse, J. P. Webster, E. Domingo, B. Charlesworth, and B. R. Levin, "Biological and biomedical implications of the co-evolution of pathogens and their hosts," Nature Genetics, vol. 32, no. 4, pp. 569-577, 2002.

[10] R. C. King, W. D. Stansfield, and P. K. Mulligan, A Dictionary of Genetics, Oxford University Press, Oxford, UK, 7th edition, 2006.

[11] N. Takahata, "A simple genealogical structure of strongly balanced allelic lines and trans-species evolution of polymorphism," Proceedings of the National Academy of Sciences of the United States of America, vol. 87, no. 7, pp. 2419-2423, 1990.

[12] P. W. Hedrick, "Pathogen resistance and genetic variation at MHC loci," Evolution, vol. 56, no. 10, pp. 1902-1908, 2002.

[13] F. M. Key, J. C. Teixeira, C. de Filippo, and A. M. Andrés, "Advantageous diversity maintained by balancing selection in humans," Current Opinion in Genetics \& Development, vol. 29, pp. 45-51, 2014.

[14] S. X. Xu, W. H. Ren, S. Z. Li, F. W. Wei, K. Y. Zhou, and G. Yang, "Sequence polymorphism and evolution of three cetacean MHC genes," Journal of Molecular Evolution, vol. 69, no. 3, pp. 260-275, 2009.

[15] H. Kupfermann, W. E. Mayer, C. O’hUigin, D. Klein, and J. Klein, "Shared polymorphism between gorilla and human major histocompatibility complex DRB loci," Human Immunology, vol. 34, no. 4, pp. 267-278, 1992.

[16] N. Otting, N. G. De Groot, G. G. M. Doxiadis, and R. E. Bontrop, "Extensive Mhc-DQB variation in humans and non-human primate species," Immunogenetics, vol. 54, no. 4, pp. 230-239, 2002.

[17] Y. Go, Y. Satta, Y. Kawamoto et al., "Mhc-DRB genes evolution in lemurs," Immunogenetics, vol. 54, no. 6, pp. 403-417, 2002. 
[18] W. E. Mayer, M. Jonker, D. Klein, P. Ivanyi, G. van Seventer, and J. Klein, "Nucleotide sequences of chimpanzee MHC class I alleles: evidence for trans-species mode of evolution," The EMBO Journal, vol. 7, no. 9, pp. 2765-2774, 1988.

[19] J. Klein, A. Sato, S. Nagl, and C. O’Huigín, "Molecular transspecies polymorphism," Annual Review of Ecology and Systematics, vol. 29, pp. 1-21, 1998.

[20] J. Klein, A. Sato, and N. Nikolaidis, "MHC, TSP, and the origin of species: from immunogenetics to evolutionary genetics," Annual Review of Genetics, vol. 41, pp. 281-304, 2007.

[21] J. Klein, "Origin of major histocompatibility complex polymorphism: the trans-species hypothesis," Human Immunology, vol. 19, no. 3, pp. 155-162, 1987.

[22] S. Nagl, H. Tichy, W. E. Mayer, N. Takahata, and J. Klein, "Persistence of neutral polymorphisms in Lake Victoria cichlid fish," Proceedings of the National Academy of Sciences of the United States of America, vol. 95, no. 24, pp. 14238-14243, 1998.

[23] I. E. Samonte, Y. Satta, A. Sato, H. Tichy, N. Takahata, and J. Klein, "Gene flow between species of Lake Victoria haplochromine fishes," Molecular Biology and Evolution, vol. 24, no. 9, pp. 2069-2080, 2007.

[24] P. L. Kamath and W. M. Getz, "Adaptive molecular evolution of the Major Histocompatibility Complex genes, DRA and DQA, in the genus Equus," BMC Evolutionary Biology, vol. 11, no. 1, article 128, 2011.

[25] A. Aguilar and J. C. Garza, "Patterns of historical balancing selection on the salmonid major histocompatibility complex class II $\beta$ gene," Journal of Molecular Evolution, vol. 65, no. 1, pp. 34-43, 2007.

[26] L. Li, X. P. Zhou, and X. L. Chen, "Characterization and evolution of MHC class II B genes in ardeid birds," Journal of Molecular Evolution, vol. 72, no. 5-6, pp. 474-483, 2011.

[27] J. Klein, "Generation of diversity at MHC loci: implications for T-cell receptor repertoires," in Immunology 80, M. Fougerau and J. Dausset, Eds., pp. 239-253, Academic Press, London, UK, 1980.

[28] B. Arden and J. Klein, "Biochemical comparison of major histocompatibility complex molecules from different subspecies of Mus musculus: evidence for trans-specific evolution of alleles," Proceedings of the National Academy of Sciences of the United States of America, vol. 79, no. 7, pp. 2342-2346, 1982.

[29] A. L. Hughes and M. Yeager, "Natural selection at major histocompatibility complex loci of vertebrates," Annual Review of Genetics, vol. 32, pp. 415-435, 1998.

[30] K. J. M. Jeffery and C. R. M. Bangham, "Do infectious diseases drive MHC diversity?" Microbes and Infection, vol. 2, no. 11, pp. 1335-1341, 2000.

[31] M. Milinski, "The major histocompatibility complex, sexual selection, and mate choice," Annual Review of Ecology, Evolution, and Systematics, vol. 37, pp. 159-186, 2006.

[32] M. Yeager and A. L. Hughes, "Evolution of the mammalian MHC: natural selection, recombination, and convergent evolution," Immunological Reviews, vol. 167, pp. 45-58, 1999.

[33] D. Meyer and G. Thomson, "How selection shapes variation of the human major histocompatibility complex: a review," Annals of Human Genetics, vol. 65, pp. 1-26, 2001.

[34] L. G. Spurgin and D. S. Richardson, "How pathogens drive genetic diversity: MHC, mechanisms and misunderstandings," Proceedings of the Royal Society B: Biological Sciences, vol. 277, no. 1684, pp. 979-988, 2010.
[35] K. M. Wegner, M. Kalbe, H. Schaschl, and T. B. H. Reusch, "Parasites and individual major histocompatibility complex diversity - an optimal choice?" Microbes and Infection, vol. 6, no. 12, pp. 1110-1116, 2004.

[36] S. Sommer, "The importance of immune gene variability (MHC) in evolutionary ecology and conservation," Frontiers in Zoology, vol. 2, article 16, 2005.

[37] S. V. Edwards and P. W. Hedrick, "Evolution and ecology of MHC molecules: from genomics to sexual selection," Trends in Ecology \& Evolution, vol. 13, no. 8, pp. 305-311, 1998.

[38] J. Neefjes, M. L. M. Jongsma, P. Paul, and O. Bakke, “Towards a systems understanding of MHC class I and MHC class II antigen presentation," Nature Reviews Immunology, vol. 11, no. 12 , pp. 823-836, 2011.

[39] J. Trowsdale, “The MHC, disease and selection," Immunology Letters, vol. 137, no. 1-2, pp. 1-8, 2011.

[40] H.-J. Wallny, D. Avila, L. G. Hunt et al., "Peptide motifs of the single dominantly expressed class I molecule explain the striking MHC-determined response to Rous sarcoma virus in chickens," Proceedings of the National Academy of Sciences of the United States of America, vol. 103, no. 5, pp. 1434-1439, 2006.

[41] D. J. Penn and W. K. Potts, "The evolution of mating preferences and major histocompatibility complex genes," American Naturalist, vol. 153, no. 2, pp. 145-164, 1999.

[42] J. M. Vyas, A. G. van der Veen, and H. L. Ploegh, “The known unknowns of antigen processing and presentation," Nature Reviews Immunology, vol. 8, no. 8, pp. 607-618, 2008.

[43] L. Bernatchez and C. Landry, "MHC studies in nonmodel vertebrates: what have we learned about natural selection in 15 years?" Journal of Evolutionary Biology, vol. 16, no. 3, pp. 363377,2003

[44] E. Ottová, A. Šimková, J.-F. Martin et al., "Evolution and transspecies polymorphism of $M H C$ class II $\beta$ genes in cyprinid fish," Fish \& Shellfish Immunology, vol. 18, no. 3, pp. 199-222, 2005.

[45] D. H. Bos and B. Waldman, "Evolution by recombination and transspecies polymorphism in the MHC class I gene of Xenopus laevis," Molecular Biology and Evolution, vol. 23, no. 1, pp. 137$143,2006$.

[46] S. Glaberman and A. Caccone, "Species-specific evolution of class I MHC genes in iguanas (Order: Squamata; Subfamily: Iguaninae)," Immunogenetics, vol. 60, no. 7, pp. 371-382, 2008.

[47] K. T. Ballingall, M. S. Rocchi, D. J. McKeever, and F. Wright, "Trans-species polymorphism and selection in the MHC class II DRA genes of domestic sheep," PLoS ONE, vol. 5, no. 6, Article ID el1402, 2010

[48] E. Janova, J. Matiasovic, J. Vahala, R. Vodicka, E. van Dyk, and P. Horin, "Polymorphism and selection in the major histocompatibility complex DRA and DQA genes in the family Equidae," Immunogenetics, vol. 61, no. 7, pp. 513-527, 2009.

[49] H. Piontkivska and M. Nei, "Birth-and-death evolution in primate MHC class I genes: divergence time estimates," Molecular Biology and Evolution, vol. 20, no. 4, pp. 601-609, 2003.

[50] K. Takahashi, A. P. Rooney, and M. Nei, "Origins and divergence times of mammalian class II MHC gene clusters," Journal of Heredity, vol. 91, no. 3, pp. 198-204, 2000.

[51] K. Kriener, C. O'hUigin, and J. Klein, "Independent origin of functional MHC class II genes in humans and New World monkeys," Human Immunology, vol. 62, no. 1, pp. 1-14, 2001.

[52] S. Kundu and C. G. Faulkes, "A tangled history: patterns of major histocompatibility complex evolution in the African mole-rats (Family: Bathyergidae)," Biological Journal of the Linnean Society, vol. 91, no. 3, pp. 493-503, 2007. 
[53] M. Zhao, Y. Wang, H. Shen et al., "Evolution by selection, recombination, and gene duplication in MHC class I genes of two Rhacophoridae species," BMC Evolutionary Biology, vol. 13, no. 1, article 113, 2013.

[54] W. Jaratlerdsiri, S. R. Isberg, D. P. Higgins et al., "Evolution of MHC class I in the order crocodylia," Immunogenetics, vol. 66, no. 1, pp. 53-65, 2014.

[55] W. Jaratlerdsiri, S. R. Isberg, D. P. Higgins, L. G. Miles, and J. Gongora, "Selection and trans-species polymorphism of major histocompatibility complex class II genes in the order crocodylia," PLoS ONE, vol. 9, no. 2, Article ID e87534, 2014.

[56] I. Kiryu, J. M. Dijkstra, R. I. Sarder, A. Fujiwara, Y. Yoshiura, and M. Ototake, "New MHC class Ia domain lineages in rainbow trout (Oncorhynchus mykiss) which are shared with other fish species," Fish \& Shellfish Immunology, vol. 18, no. 3, pp. 243-254, 2005.

[57] D. Wang, L. Zhong, Q. Wei, X. Gan, and S. He, "Evolution of MHC class I genes in two ancient fish, paddlefish (Polyodon spathula) and Chinese sturgeon (Acipenser sinensis)," FEBS Letters, vol. 584, no. 15, pp. 3331-3339, 2010.

[58] W. J. Horing, E. Papagiannes, S. Dray, and L. S. Rodkey, "Expression of cross-reacting determinants of the immunoglobulin heavy chain variable region a3 allotype in Oryctolagus and Lepus," Molecular Immunology, vol. 17, no. 1, pp. 111-117, 1980.

[59] A. Pinheiro, D. Lanning, P. C. Alves et al., "Molecular bases of genetic diversity and evolution of the immunoglobulin heavy chain variable region (IGHV) gene locus in leporids," Immunogenetics, vol. 63, no. 7, pp. 397-408, 2011.

[60] C. Su and M. Nei, "Fifty-million-year-old polymorphism at an immunoglobulin variable region gene locus in the rabbit evolutionary lineage," Proceedings of the National Academy of Sciences of the United States of America, vol. 96, no. 17, pp. 9710$9715,1999$.

[61] P. J. Esteves, D. Lanning, N. Ferrand, K. L. Knight, S. K. Zhai, and W. Van Der Loo, "The evolution of the immunoglobulin heavy chain variable region $(\mathrm{IgV} \mathrm{H})$ in Leporids: an unusual case of transspecies polymorphism," Immunogenetics, vol. 57, no. 11, pp. 874-882, 2005.

[62] K. Sumiyama, S. Kawamura, O. Takenaka, and S. Ueda, "A high sequence variety in the immunoglobulin $\mathrm{C}$-alpha hinge region among old world monkeys," Anthropological Science, vol. 106, no. 1, pp. 31-39, 1998.

[63] K. Sumiyama, N. Saitou, and S. Ueda, "Adaptive evolution of the IgA hinge region in primates," Molecular Biology and Evolution, vol. 19, no. 7, pp. 1093-1099, 2002.

[64] S. Kawamura, K. Omoto, and S. Ueda, "Evolutionary hypervariability in the hinge region of the immunoglobulin alpha gene," Journal of Molecular Biology, vol. 215, no. 2, pp. 201-206, 1990.

[65] C. J. Male, "Immunoglobulin A1 protease production by Haemophilus influenzae and Streptococcus pneumoniae," Infection and Immunity, vol. 26, no. 1, pp. 254-261, 1979.

[66] H. J. Fehling, W. Swat, C. Laplace et al., "MHC class I expression in mice lacking the proteasome subunit LMP-7," Science, vol. 265, no. 5176, pp. 1234-1237, 1994.

[67] K. Tsukamoto, F. Miura, N. T. Fujito, G. Yoshizaki, and M. Nonaka, "Long-lived dichotomous lineages of the proteasome subunit beta type 8 (PSMB8) gene surviving more than 500 million years as alleles or paralogs," Molecular Biology and Evolution, vol. 29, no. 10, pp. 3071-3079, 2012.

[68] F. Miura, K. Tsukamoto, R. B. Mehta, K. Naruse, W. Magtoon, and M. Nonaka, "Transspecies dimorphic allelic lineages of the proteasome subunit $\beta$-type 8 gene (PSMB8) in the teleost genus Oryzias," Proceedings of the National Academy of Sciences of the United States of America, vol. 107, no. 50, pp. 21599-21604, 2010.

[69] M. Nonaka, C. Yamada-Namikawa, M. F. Flajnik, and L. Du Pasquier, "Trans-species polymorphism of the major histocompatibility complex-encoded proteasome subunit LMP7 in an amphibian genus, Xenopus," Immunogenetics, vol. 51, no. 3, pp. 186-192, 2000.

[70] M. Noro and M. Nonaka, "Evolution of dimorphisms of the proteasome subunit beta type 8 gene (PSMB8) in basal rayfinned fish," Immunogenetics, vol. 66, no. 5, pp. 325-334, 2014.

[71] T. Ganz, "Defensins: antimicrobial peptides of innate immunity," Nature Reviews Immunology, vol. 3, no. 9, pp. 710-720, 2003.

[72] T. Cuperus, M. Coorens, A. van Dijk, and H. P. Haagsman, "Avian host defense peptides," Developmental and Comparative Immunology, vol. 41, no. 3, pp. 352-369, 2013.

[73] S. C. Mansour, O. M. Pena, and R. E. Hancock, "Host defense peptides: front-line immunomodulators," Trends in Immunology, vol. 35, no. 9, pp. 443-450, 2014.

[74] D. M. E. Bowdish, D. J. Davidson, and R. E. W. Hancock, "A reevaluation of the role of host defence peptides in mammalian immunity," Current Protein \& Peptide Science, vol. 6, no. 1, pp. 35-51, 2005.

[75] G. S. Wang, X. Li, and Z. Wang, "APD2: the updated antimicrobial peptide database and its application in peptide design," Nucleic Acids Research, vol. 37, no. 1, pp. D933-D937, 2009.

[76] J. A. Tennessen and M. S. Blouin, "Balancing selection at a frog antimicrobial peptide locus: fluctuating immune effector alleles?" Molecular Biology and Evolution, vol. 25, no. 12, pp. 2669-2680, 2008.

[77] E. J. Hollox and J. A. L. Armour, "Directional and balancing selection in human beta-defensins," BMC Evolutionary Biology, vol. 8, article 113, 2008.

[78] O. Hellgren and B. C. Sheldon, "Locus-specific protocol for nine different innate immune genes (antimicrobial peptides: $\beta$ defensins) across passerine bird species reveals within-species coding variation and a case of trans-species polymorphisms," Molecular Ecology Resources, vol. 11, no. 4, pp. 686-692, 2011.

[79] L. Braida, M. Boniotto, A. Pontillo, P. A. Tovo, A. Amoroso, and S. Crovella, "A single-nucleotide polymorphism in the human beta-defensin 1 gene as associated with HIV-1 infection in Italian children," AIDS, vol. 18, no. 11, pp. 1598-1600, 2004.

[80] W. E. Johnson and S. L. Sawyer, "Molecular evolution of the antiretroviral TRIM5 gene," Immunogenetics, vol. 61, no. 3, pp. 163-176, 2009.

[81] M. Stremlau, C. M. Owens, M. J. Perron, M. Kiessling, P. Autissier, and J. Sodroski, "The cytoplasmic body component TRIM5alpha restricts HIV-1 infection in Old World monkeys," Nature, vol. 427, no. 6977, pp. 848-853, 2004.

[82] R. M. Newman, L. Hall, M. Connole et al., "Balancing selection and the evolution of functional polymorphism in Old World monkey TRIM5 $\alpha$," Proceedings of the National Academy of Sciences of the United States of America, vol. 103, no. 50, pp. 19134-19139, 2006.

[83] R. Cagliani, M. Fumagalli, M. Biasin et al., "Long-term balancing selection maintains trans-specific polymorphisms in the human TRIM5 gene," Human Genetics, vol. 128, no. 6, pp. 577$588,2010$. 
[84] A. G. Hovanessian and J. Justesen, “The human $2^{\prime}-5^{\prime}$ oligoadenylate synthetase family: unique interferon-inducible enzymes catalyzing $2^{\prime}-5^{\prime}$ instead of $3^{\prime}-5^{\prime}$ phosphodiester bond formation," Biochimie, vol. 89, no. 6-7, pp. 779-788, 2007.

[85] T. Mashimo, M. Lucas, D. Simon-Chazottes et al., "A nonsense mutation in the gene encoding $2^{\prime}-5^{\prime}$-oligoadenylate synthetase/L1 isoform is associated with West Nile virus susceptibility in laboratory mice," Proceedings of the National Academy of Sciences of the United States of America, vol. 99, no. 17, pp. 11311-11316, 2002.

[86] A. A. Perelygin, S. V. Scherbik, I. B. Zhulin, B. M. Stockman, Y. Li, and M. A. Brinton, "Positional cloning of the murine flavivirus resistance gene," Proceedings of the National Academy of Sciences of the United States of America, vol. 99, no. 14, pp. 9322-9327, 2002.

[87] W. Ferguson, S. Dvora, J. Gallo, A. Orth, and S. Boissinot, "Long-term balancing selection at the West Nile virus resistance gene, Oaslb, maintains transspecific polymorphisms in the house mouse," Molecular Biology and Evolution, vol. 25, no. 8, pp. 1609-1618, 2008.

[88] W. Ferguson, S. Dvora, R. W. Fikes, A. C. Stone, and S. Boissinot, "Long-term balancing selection at the antiviral gene OAS1 in central African chimpanzees," Molecular Biology and Evolution, vol. 29, no. 4, pp. 1093-1103, 2012.

[89] T. R. Ioerger, A. G. Clark, and T.-H. Kao, "Polymorphism at the self-incompatibility locus in Solanaceae predates speciation," Proceedings of the National Academy of Sciences of the United States of America, vol. 87, no. 24, pp. 9732-9735, 1990.

[90] A. D. Richman, M. K. Uyenoyama, and J. R. Kohn, "Allelic diversity and gene genealogy at the self-incompatibility locus in the solanaceae," Science, vol. 273, no. 5279, pp. 1212-1216, 1996.

[91] K. G. Dwyer, M. A. Balent, J. B. Nasrallah, and M. E. Nasrallah, "DNA sequences of self-incompatibility genes from Brassica campestris and B. oleracea: polymorphism predating speciation," Plant Molecular Biology, vol. 16, no. 3, pp. 481-486, 1991.

[92] L. Lukens, H. Yicun, and G. May, "Correlation of genetic and physical maps at the A mating-type locus of Coprinus cinereus," Genetics, vol. 144, no. 4, pp. 1471-1477, 1996.

[93] C. A. Muirhead, N. Louise Glass, and M. Slatkin, "Multilocus self-recognition systems in fungi as a cause of trans-species polymorphism," Genetics, vol. 161, no. 2, pp. 633-641, 2002.

[94] L. T. A. van Diepen, A. Olson, K. Ihrmark, J. Stenlid, and T. Y. James, "Extensive trans-specific polymorphism at the mating type locus of the root decay fungus heterobasidion," Molecular Biology and Evolution, vol. 30, no. 10, pp. 2286-2301, 2013.

[95] N. Kermarrec, F. Roubinet, P.-A. Apoil, and A. Blancher, "Comparison of allele $\mathrm{O}$ sequences of the human and nonhuman primate ABO system," Immunogenetics, vol. 49, no. 6 , pp. 517-526, 1999.

[96] J. M. Martinko, V. Vincek, D. Klein, and J. Klein, "Primate ABO glycosyltransferases: evidence for trans-species evolution," Immunogenetics, vol. 37, no. 4, pp. 274-278, 1993.

[97] L. Ségurel, E. E. Thompson, T. Flutre et al., "The ABO blood group is a trans-species polymorphism in primates," Proceedings of the National Academy of Sciences of the United States of America, vol. 109, no. 45, pp. 18493-18498, 2012.

[98] S. Lechner, L. Ferretti, C. Schöning, W. Kinuthia, D. Willemsen, and M. Hasselmann, "Nucleotide variability at its limit? Insights into the number and evolutionary dynamics of the sex-determining specificities of the honey bee apis mellifera," Molecular Biology and Evolution, vol. 31, no. 2, pp. 272-287, 2014.
[99] G. E. Heimpel and J. G. de Boer, "Sex determination in the hymenoptera," Annual Review of Entomology, vol. 53, pp. 209230, 2008.

[100] E. M. Leffler, Z. Gao, S. Pfeifer et al., "Multiple instances of ancient balancing selection shared between humans and chimpanzees," Science, vol. 340, no. 6127, pp. 1578-1582, 2013.

[101] K. Acevedo-Whitehouse and A. A. Cunningham, "Is MHC enough for understanding wildlife immunogenetics?" Trends in Ecology and Evolution, vol. 21, no. 8, pp. 433-438, 2006.

[102] T. H. Mogensen, "Pathogen recognition and inflammatory signaling in innate immune defenses," Clinical Microbiology Reviews, vol. 22, no. 2, pp. 240-273, 2009.

[103] M. S. Lee and Y. J. Kim, "Signaling pathways downstream of pattern-recognition receptors and their cross talk," Annual Review of Biochemistry, vol. 76, pp. 447-480, 2007.

[104] O. Takeuchi and S. Akira, "Pattern recognition receptors and inflammation," Cell, vol. 140, no. 6, pp. 805-820, 2010.

[105] M. Vinkler, H. Bainová, and J. Bryja, "Protein evolution of Tolllike receptors 4, 5 and 7 within Galloanserae birds," Genetics Selection Evolution, vol. 46, article 72, 2014.

[106] A. Fornuskova, J. Bryja, M. Vinkler, M. Macholán, and J. Piálek, "Contrasting patterns of polymorphism and selection in bacterial-sensing toll-like receptor 4 in two house mouse subspecies," Ecology and Evolution, vol. 4, no. 14, pp. 2931-2944, 2014.

[107] M. Alcaide and S. V. Edwards, "Molecular evolution of the tolllike receptor multigene family in birds," Molecular Biology and Evolution, vol. 28, no. 5, pp. 1703-1715, 2011.

[108] B. Ferwerda, M. B. B. McCall, S. Alonso et al., "TLR4 polymorphisms, infectious diseases, and evolutionary pressure during migration of modern humans," Proceedings of the National Academy of Sciences of the United States of America, vol. 104, no. 42, pp. 16645-16650, 2007.

[109] M. Vinkler, H. Bainová, A. Bryjová, O. Tomášek, T. Albrecht, and J. Bryja, "Characterisation of Toll-like receptors 4, 5 and 7 and their genetic variation in the grey partridge," Genetica, vol. 143, no. 1, pp. 101-112, 2015.

[110] A. Ferrer-Admetlla, E. Bosch, M. Sikora et al., "Balancing selection is the main force shaping the evolution of innate immunity genes," Journal of Immunology, vol. 181, no. 2, pp. 1315-1322, 2008.

[111] D. A. Loisel, M. V. Rockman, G. A. Wray, J. Altmann, and S. C. Alberts, "Ancient polymorphism and functional variation in the primate MHC-DQA1 5' cis-regulatory region," Proceedings of the National Academy of Sciences of the United States of America, vol. 103, no. 44, pp. 16331-16336, 2006.

[112] P. W. Hedrick, "Adaptive introgression in animals: examples and comparison to new mutation and standing variation as sources of adaptive variation," Molecular Ecology, vol. 22, no. 18, pp. 4606-4618, 2013.

[113] K. M. Wegner and C. Eizaguirre, "New(t)s and views from hybridizing MHC genes: introgression rather than trans-species polymorphism may shape allelic repertoires," Molecular Ecology, vol. 21, no. 4, pp. 779-781, 2012.

[114] K. Kriener, C. O’hUigin, H. Tichy, and J. Klein, “Convergent evolution of major histocompatibility complex molecules in humans and New World monkeys," Immunogenetics, vol. 51, no. 3, pp. 169-178, 2000.

[115] V. Vincek, C. O'Huigin, Y. Satta et al., "How large was the founding population of Darwin's finches?" Proceedings of the Royal Society B: Biological Sciences, vol. 264, no. 1378, pp. 111118, 1997. 
[116] A. Sato, H. Tichy, P. R. Grant, B. R. Grant, T. Sato, and C. O'Huigin, "Spectrum of MHC class II variability in Darwin's finches and their close relatives," Molecular Biology and Evolution, vol. 28, no. 6, pp. 1943-1956, 2011.

[117] P. R. Grant and B. R. Grant, "Hybridization of bird species," Science, vol. 256, no. 5054, pp. 193-197, 1992.

[118] C. Grossen, L. Keller, I. Biebach, D. Croll, and International Goat Genome Consortium, "Introgression from domestic goat generated variation at the major histocompatibility complex of alpine ibex," PLoS Genetics, vol. 10, no. 6, Article ID e1004438, 2014.

[119] K. Nadachowska-Brzyska, P. Zieliński, J. Radwan, and W. Babik, "Interspecific hybridization increases MHC class II diversity in two sister species of newts," Molecular Ecology, vol. 21, no. 4, pp. 887-906, 2012.

[120] A. Šimková, K. Civáňová, L. Gettová, and A. Gilles, “Genomic porosity between invasive Chondrostoma nasus and endangered endemic Parachondrostoma toxostoma (Cyprinidae): the evolution of MHC IIB genes," PLoS ONE, vol. 8, no. 6, Article ID e65883, 2013.

[121] C. Van Oosterhout, "A new theory of MHC evolution: beyond selection on the immune genes," Proceedings of the Royal Society B: Biological Sciences, vol. 276, no. 1657, pp. 657-665, 2009. 


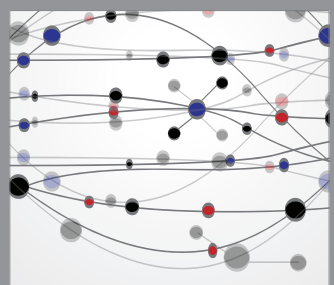

The Scientific World Journal
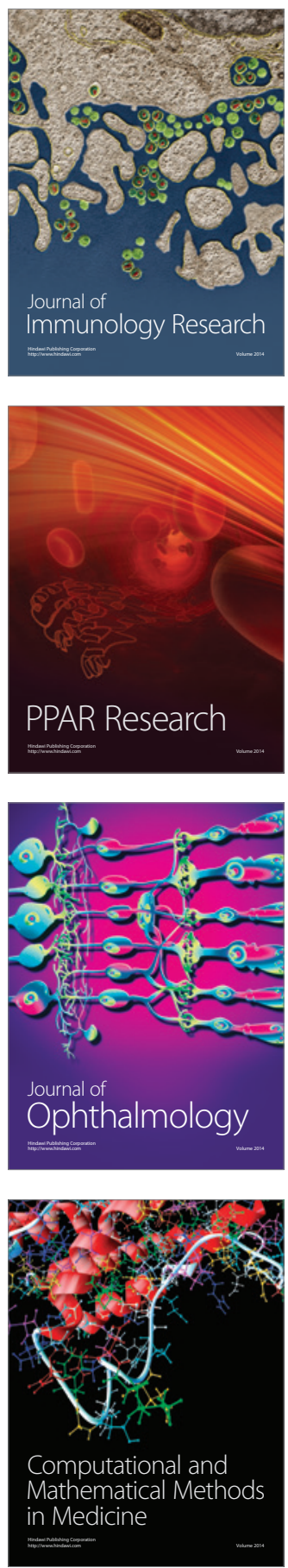

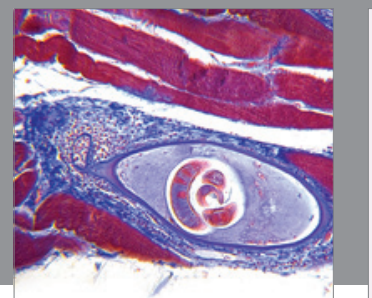

Gastroenterology

Research and Practice
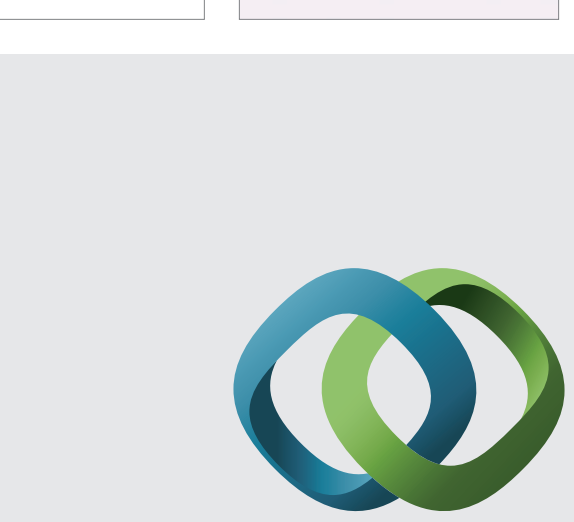

\section{Hindawi}

Submit your manuscripts at

http://www.hindawi.com
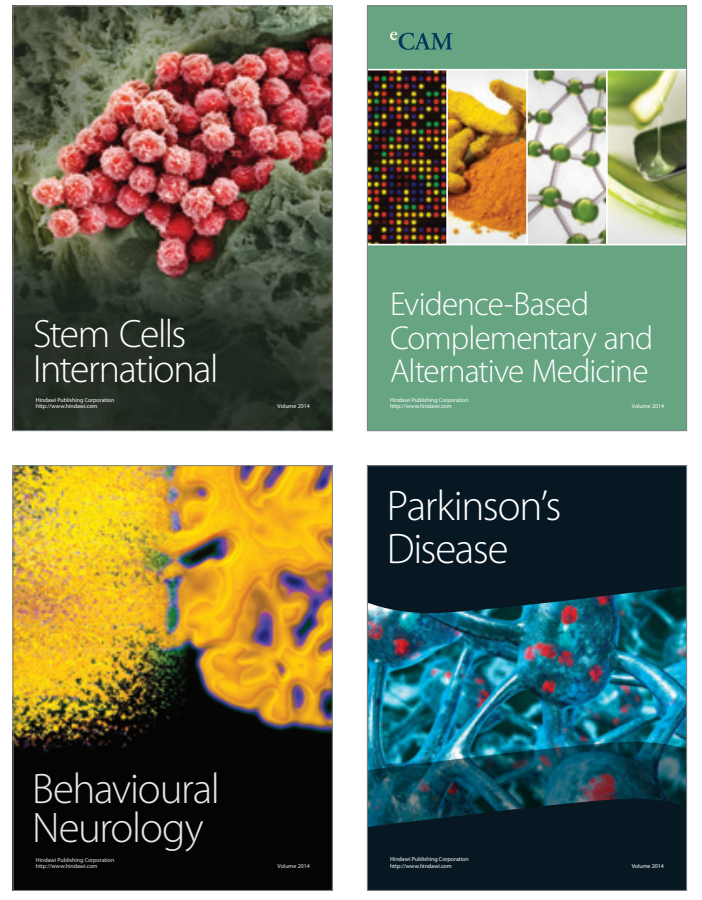
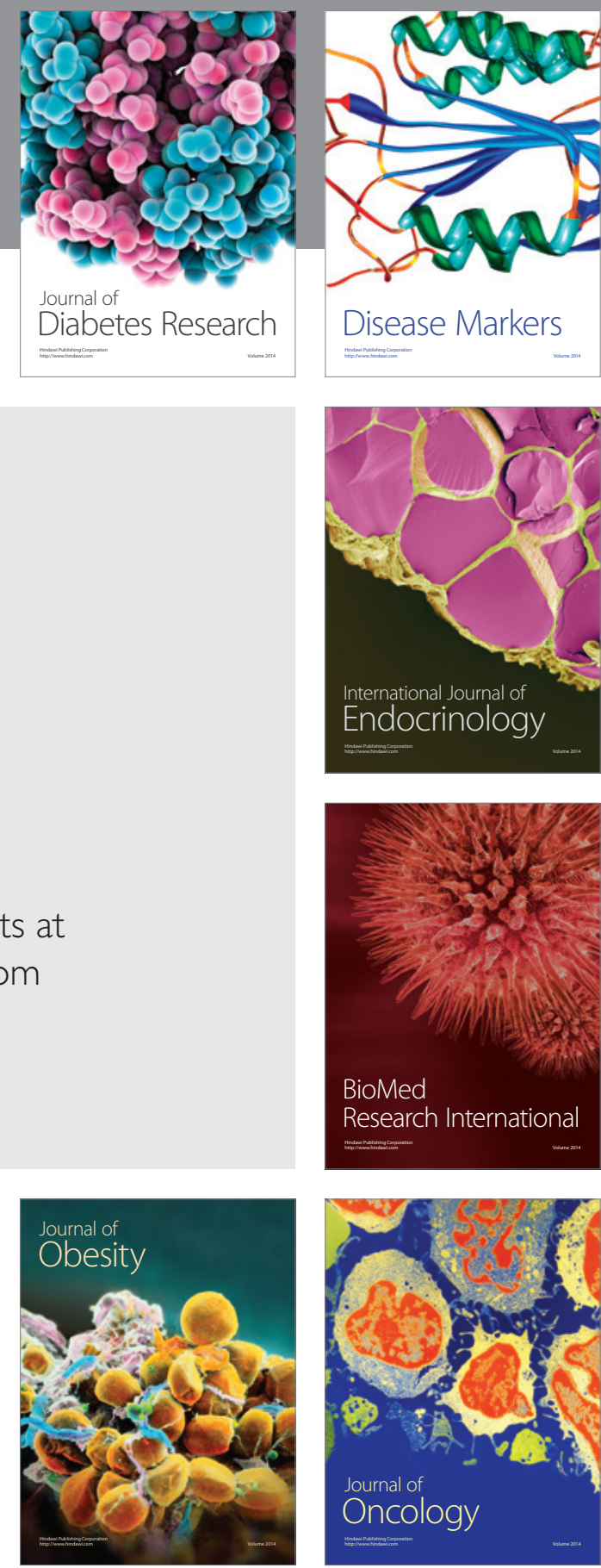

Disease Markers
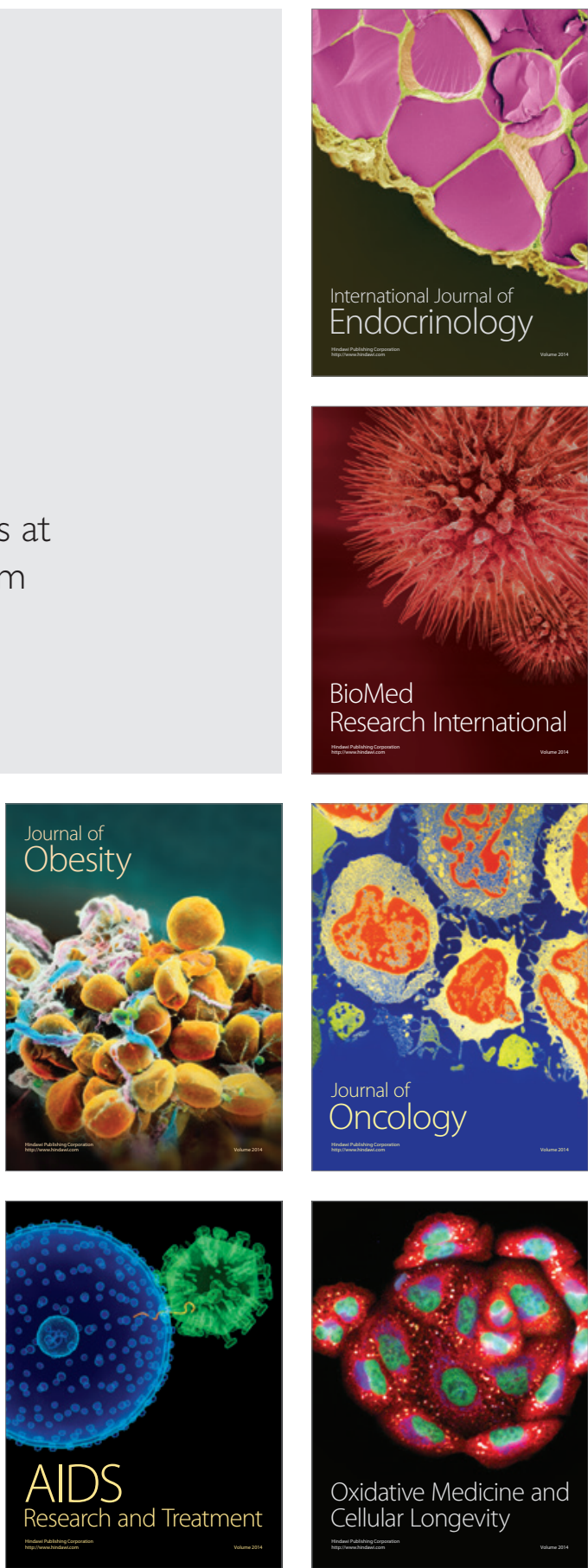